\title{
Y nos mandaron a hacer viñetas
}

\section{De locuras e ilusiones tebeísticas \\ en la Zaragoza de los ochenta}

Fernando de Felipe ${ }^{1}$

La memoria, indispensable y portentosa, es también frágil y vulnerable. No está amenazada sólo por el olvido, su viejo enemigo, sino también por los falsos recuerdos que van invadiéndola día tras día.

Luis Buñuel

Estamos cometiendo la locura de dejar de ser locos.

Antonio Altarriba

\section{INTROITO: COMO DIRÍA EL CLÁSICO, «EX NIHILO NIHIL FIT»}

Hubo un tiempo en este país de las pretendidas maravillas que era la España de la Transición, en el que un dibujante de cómics podía atravesar de punta a punta la península (islas inclusive) sin gastar una sola peseta de su propio bolsillo. Raro era el municipio, por humilde, pintoresco o remoto que fuera, que no contase entre sus autoridades con un voluntarioso concejal de cultura empeñado en montar algún tipo de evento popular relacionado directamente con todo eso de las viñetas. Aunque ahora suene raro, en aquel tiempo remoto y ya irrecuperable los alcaldables de turno no iban por ahí prometiendo polideportivos completamente equipados ni, por supuesto, acceso wifi gratuito en toda la localidad, sino festejos más o menos bien comisariados que tuvieran que ver con los tebeos. Y ya de paso, con los que los hacían. Seguramente fue por eso que muchos creyeron que, movidas (madrileñas) aparte, «la Transición sería quiosquizada o no sería».

A mí me pasó. Lo de poder recorrerme el país de arriba abajo a cargo de las arcas públicas y lo de creerme en la parrilla de salida rumbo hacia una nueva era.

\footnotetext{
1 Dr. Fernando de Felipe, Universitat Ramon Llull.
} 
Aprovecho para advertir que éste no será un artículo académico al uso, más que nada porque lo académico casa mal con los exámenes de conciencia preparados a golpe de nostalgia y las memorias no opositables a notarías. Aunque, ya que hablamos de notarías, tampoco estará de más que diga que sí, que como buen Abuelo Cebolleta en modo Cuéntame, intentaré levantar abocetada acta a partir de mis propios recuerdos sobre aquellos maravillosos años, tan apasionados e irrepetibles como entrañablemente ingenuos, alocados y fructíferos.

\section{RETRATO DE UN HISTORIETISTA ADOLESCENTE}

A mí, que soy de la quinta del 65 del pasado siglo, los ochenta me pillaron a medio cocer. La cosa al principio tuvo mucho de espejismo, algo perfectamente normal en una Zaragoza orgullosamente autoproclamada «capital del desierto». Situada exactamente a mitad de camino entre el Madrid de «la movida» y la Barcelona previa al «movidón preolímpico», Zaragoza no era precisamente el mejor destino (ni el mejor origen) para alguien que, como era mi caso, quisiera dedicarse profesionalmente a eso de los tebeos.

Cabezón más allá de lo autonómicamente correcto, mi pasión por las viñetas venía de lejos, y poco o nada tuvo que ver con aquella campaña teñida de gris que lanzó en 1976 el Ministerio de Información y Turismo al desarrollista grito de «Donde hay un tebeo habrá un libro». En mi caso fue más bien al contrario, teniendo como tuve la inmensa suerte de ser nieto de Don Antonio Allué, un librero «de viejo», bohemio hasta las trancas, que fue el mejor mal ejemplo con el que nunca pude soñar. La centenaria Librería Allué, que yo conocí en su segunda ubicación en la calle Estébanes, fue desde siempre mi segunda casa, una auténtica madriguera en la que, rodeado por igual de libros de segunda mano, ediciones de bibliófilo, grabados, postales antiguas, programas de cine, novelas de «a duro» y tebeos comprados a peso, terminé desarrollando ese sexto sentido como lector omnívoro, heterodoxo y compulsivo que tanto me ayudaría a la hora de franquear mi particular línea de sombra comiquera.

Como casi todos los chavales de mi generación, los tebeos que solía leer eran los que podían encontrarse tanto en la sección de infantil y juvenil de cualquier librería o biblioteca mínimamente surtida, como, sobre todo, en aquellos atiborradísimos quioscos en los que revistas como Pulgarcito llegaban a vender la friolera de 240.000 ejemplares a la semana. Mi dieta 
básica como aficionado a la historieta (y cito de memoria) pasaba por coger ingredientes de proximidad como el TBO, Tío Vivo, Din Dan, Jaimito, Pumby, el dramatis personae al completo de Bruguera, las Hazañas Bélicas de Boixcar o El Capitán Trueno (aunque yo era más de El Jabato), y saltearlos indiscriminadamente con productos que podían ir de las rancias tebeizaciones que de los grandes clásicos de las letras universales hacían colecciones como Joyas Literarias Juveniles, a los afrancesados aromas alla Pilote de la revista Trinca, pasando por los siempre nutritivos fascículos de Buru Lan dedicados a los principales iconos de las tiras de prensa estadounidense (El Hombre Enmascarado, El Príncipe Valiente, Rip Kirby, Carlitos, Popeye), por aquellos «picadillos Marvel» que nos servían debidamente recalentados los de la chapucera Vértice, o por las delicatessen franco-belgas tipo Tintín, Astérix, Spirou o Lucky Luke.

Si tenías suerte (y tus padres, maestros y confesores no se enteraban), podías picotear entre horas exquisiteces «para adultos» tan suculentas como las servidas mensualmente por Dossier Negro, Vampus, Rufus, Vampirella, Drácula, Zarpa de acero, Spirit o Delta 99, degustar las mejores recetas underground de Star, Bésame mucho y El Rrollo enmascarado, e incluso tapear a placer gracias a todas esas raciones de enrabietada actualidad que nos ofrecían El Jueves o El Papus, semanarios satíricos que por aquel entonces ya eran todo lo políticamente incorregibles (y judicialmente perseguibles) que cabía esperar.

Como digo, a mí el «boom» del cómic adulto (y de autor) me cogió bastante curtido, y apenas me sorprendió ver cómo los quioscos a los que antes peregrinaba con fervor de auténtica beata para comprar El DDT, el último Doc Savage o mi ración semanal de Mortadelo, comenzaban a ser tomados al asalto, literalmente, por muchas más revistas de cómic de las que cualquier bolsillo medio podía permitirse. Por un momento pareció que en los quioscos de la Transición podían llegar a tirar más cuatro viñetas que dos tetas (y eso que estábamos en pleno apogeo del «destape» y de publicaciones eróticas tipo Interviú o Lib).

En apenas un par de años las nuevas cabeceras empezaron a multiplicarse exponencialmente mes a mes, haciendo realmente difícil decidir por cuáles apostar y cuáles dejar para mejor ocasión. El listado, siempre incompleto, incluiría títulos tan emblemáticos, inspiradores y apetitosos como Totem, Bumerang, Blue Jeans, Métal Hurlant, 1984, Ilustración + Comix internacional, Cimoc, Creepy, El Víbora, Cairo, Epic, Vértigo, Metropol, Rambla, Makoki o la subvencionadísima Madriz. En algunas de ellas, con los 
años, terminé publicando ya como profesional a tiempo completo; el resto las seguí consumiendo con idéntica pasión. Al menos, mientras duraron.

Visto en perspectiva, y dada la magnitud de tan inflacionista burbuja tebeística, sorprende sin duda que en apenas dos décadas los cómics acabasen desapareciendo casi por completo de nuestros quioscos, lamentable pérdida de visibilidad mediática, arraigo popular, musculatura industrial y potencialidad comunicativa de la que, incluso hoy, seguimos sin reponernos del todo. Cosas de la gentrificación cultural, supongo.

\section{CONTEXTUALIZANDO EL DESCONTEXTO}

Es verdad que los ochenta supusieron un reconocimiento sin precedentes del cómic como impertinente candidato a las reivindicaciones propias de la alta cultura. De la noche a la mañana, lo que antes era puro (cuando no pueril) entretenimiento popular en clave más o menos desarrollista, comenzó a gozar de un aparente prestigio que poco a poco fue colándose por todos los rincones. Subidón democrático mediante, pasamos de las censuras atávicas y el ninguneo cultural a convertir los tebeos en lo que ahora llamaríamos una «tendencia» al alza. El cómic podía rastrearse ya hasta en la hoja parroquial, convirtiéndose en un ingrediente casi imprescindible en sectores tan dispares como la prensa, la televisión (entonces únicamente pública), la literatura más seria y comprometida, el cine más o menos (pos)moderno, el arte contemporáneo, la publicidad, el diseño, la música e incluso el ámbito estrictamente académico.

Como diría el gran José Luis Cuerda, de sabernos contingentes pasamos a creernos necesarios, sobre todo después de constatar que el pop resultaba mucho más pop si incluía referencias al mundo de las viñetas. Los discos comenzaron a lucir portadas que eran pura historieta, y no costaba esfuerzo alguno toparte con canciones, y hasta con grupos, cuyos nombres estaban directamente inspirados en personajes o revistas de cómic. Una auténtica locura. Pasajera, pero locura al fin y al cabo.

Y eso que hacía realmente poco que habíamos descubierto que el Jean Giraud de Blueberry era el mismo Moebius de El garaje hermético; que Tintín podía leerse como estructura ausente; que el poderoso influjo de la historieta, también conocida como «el cine de los pobres», estaba detrás de superproducciones hollywoodienses tan influyentes como Alien, Blade Runner, Tron o Dune; que los agrios desencuentros identitarios entre los seguidores de la «línea clara» y los defensores de la «línea chunga» bien 
podían equipararse a aquellas batallitas campales que libraban rockers y mods en las quadrophénicas arenas de Brighton; que el manga, prácticamente inédito por estos lares en aquellas fechas, podía llegar a ser la verdadera amenaza en la sombra de cara a la supervivencia del sector; o que las tesis doctorales defendidas por francotiradores tan visionarios y voluntariosos como mi admirado Antonio Altarriba, podían ya citar a quemarropa, y sin miedo a lo que pudieran opinar los tribunales competentes, las piruetas ensayísticas de pioneros del medio como Gubern, Moix, Acevedo, Ramírez, Martín, Gasca, Lara, Paramio, Cuadrado o Coma.

De hecho, y tal como había ocurrido ya antes con el cine y la fotografía (y más tarde acabaría pasando con el diseño, la gamificación o el transmedia), fue en los mismísimos márgenes de ciertas universidades donde la «narrativa secuencial» pasó de ser considerada tan solo como un objeto de estudio más o menos interesante, inexplorado o «moderno», a convertirse en una disciplina académica de pleno derecho. $\mathrm{Y}$ eso sí que resultó realmente revolucionario.

Lo cierto es que tardamos bien poco en ponernos metalingüísticos, cuando no semióticos perdidos, y raro era el dibujante y/o guionista, consagrado o por consagrar, que no intentara reventar las costuras del medio al más puro estilo Duchamp (o similares) en cuanto se le presentaba la menor ocasión. Y ocasiones hubo muchas, tanto dentro como fuera de las aulas. Incluso aquí, en plena «capital del desierto».

\section{MIENTRAS TANTO, EN ZARAGOZA...}

Para ser justos del todo, conviene que rebobinemos un poco y no adelantemos acontecimientos. Más que nada, porque antes de que todo lo anteriormente expuesto pasara, en la ninguneada Zaragoza de finales de los setenta ya se hablaba de las contraculturales andanzas de «los Zetas», un puñado de irreductibles fanzinerosos que pretendían poner en marcha un ambicioso programa de acción gráfica basado en las posibilidades narrativas de la imagen (léase «cómic», pero léase bien).

Atrincherados al principio alrededor de ese auténtico «escándalo público y atentado a la moral católica» (sic) que fue la revista Zeta, y más tarde reorganizados como grupo Bustrófedon (paradójico nombre para un colectivo de idealistas que en esto de los tebeos siempre pensó que era posible tirar del carro poniéndolo delante de los bueyes), yo no los conocí personalmente hasta el día en que la Universidad Popular de Zaragoza, aprovechando 
seguramente que yo ya venía publicando mis asilvestrados «monigotes» en el Heraldo de Aragón, me contrató para impartir un taller de cómic para adultos junto a uno de sus principales miembros, el entrañable Samuel Aznar, maravilloso ilustrador, certero diseñador y mejor persona.

La experiencia fue divertidísima (no en vano tuvimos como «alumnos» a tipos tan brillantes como Víctor Gomollón o Alberto «Supermaño» Calvo), y una vez finalizada me dio la oportunidad de seguir estando todo lo cerca que fuera posible - para ver si, ya puestos, se me pegaba algo - de gente tan talentosa como Luis Royo, Ricardo Joven, Strader o el propio Altarriba, que entonces ejercía de brazo teórico-ideológico del grupo.

Tras vivir de primera mano la creación de las más que ilusionantes primeras Jornadas Culturales del cómic de Zaragoza, y justo después de asistir al nacimiento de la mítica revista Neuróptica, en 1983 puse rumbo por fin a la preolímpica Barcelona, fascinante ciudad cargada de posibilidades académicas, vitales y editoriales en la que, sin perder nunca del todo el contacto con los de Bustrófedon (a través del TVO, por ejemplo), comencé a cursar mis estudios universitarios en la Facultad de Bellas Artes (en Zaragoza, lógicamente, no teníamos de eso).

Y fue precisamente allí, al amparo de mis buenos amigos del Taka de Tinta, de mis alocados compañeros de promoción, y de un no menos enloquecido grupo de profesores que intentaron hacer de mí todo un académico de pro, donde terminé centrando mi cabecita, definiendo mi vocación, buscándome la vida, y ya que estaba, labrándome pasito a pasito un prometedor futuro como profesional del cómic. De algún modo, el círculo quedaba definitivamente cerrado. Aunque fuese apelando a su propia cuadratura. Pero eso, lógicamente, es ya otra historieta. 